\title{
The sister chromatid exchange test as an indicator of marine pollution: some factors affecting SCE frequencies in Mytilus galloprovincialis
}

\author{
J. J. Pasantes ${ }^{1, *}$, M. J. Martínez-Expósito ${ }^{1}$, A. Torreiro ${ }^{1}$, J. Méndez ${ }^{2}$ \\ ${ }^{1}$ Dpto Bioloxía Fundamental, Xenética, Universidade de Vigo, E-36200 Vigo, Spain \\ ${ }^{2}$ Dpto Bioloxía Celular e Molecular, Xenética, Universidade da Coruña, E-15071 A Coruña, Spain
}

\begin{abstract}
The sister chromatid exchange ( $S C E$ ) test is a widely used method to detect chemically induced genetic damage. This method has been applied in some aquatic species to monitor genetic pollutants in estuarine and marine environments. Dose response to 5-bromodeoxyuridine (BrdU) was investigated in the mussel Mytilus galloprovincialis Lmk. Experimental assays were carried out by incorporating $4,10,20$ and $40 \mathrm{\mu g} \mathrm{ml}^{-1}$ BrdU in asynchronously growing mussel gill cell populations. SCE frequency was dose dependent both for mussel cells labelled with BrdU for a first round of replication followed by a second round without BrdU $(24+36 \mathrm{~h})$, and for mussel cells labelled with BrdU for 2 consecutive rounds of replication $(60 \mathrm{~h})$. For every dose assayed, significant differences in SCE frequencies were also found between these 2 kinds of BrdU treatments. The relationship between the duration of the BrdU treatment and the frequency of SCEs was also investigated in M. galloprovincialis. We tested the effect of in vivo BraU incorporation for either the first cell cycle, or the first and second cell cycles in mussel gill cells. This paper shows that SCE frequencies remain constant for the different BrdU exposures $(12+36,12+48,24+24,24+36$ and $36+24$ h) assayed to obtain first cell cycle labelling, but a striking increase was noted in BrdU treatments $(48,60,72,84$ and $96 \mathrm{~h})$ for 2 consecutive cycles of labelling. A monthly study of SCE frequencies occurring in 2 natural populations from NW Spain was also performed during 1993. Significant differences in the frequency of SCE were detected both between populations and among months in the mussel populations. In most of the cases, noticeable interindividual variations in SCE frequencies were detected in mussels exposed to the same BrdU conditions.
\end{abstract}

KEY WORDS: 5-Bromodeoxyuridine (BrdU) Biomonitoring - Mytilus galloprovincialis - Sister Chromatid Exchange (SCE)

\section{INTRODUCTION}

Differential staining of metaphase chromosomes based on the effects of substitution of 5-bromodeoxyuridine (BrdU) for thymidine in DNA has been extensively employed to detect sister chromatid exchanges (SCEs) in many mutagen-carcinogen assays. The in vivo application of this technique opened a new realm for the screening of environmental pollutants because the results obtained in vivo provide a close approximation to reality, and activation

•E-maik: pasantes@setei.uvigo.es and/or inactivation of mutagens and carcinogens can be readily monitored (Schneider et al. 1978).

The toxicological implications of increased levels of contaminants in estuarine and coastal waters is a matter of considerable environmental concern; therefore some systems have been assayed to monitor the genotoxicity of marine pollutants. In aquatic organisms, some reports have been published using modifications of the fluorescence-plus-Giemsa (FPG) method (Perry $\&$ Wolff 1974) to produce sister-chromatid differentiation (SCD) in chromosomes and, thus, to detect SCEs. Fishes such as Umbra species (Kligerman \& Bloom 1976) and Nothobranchius rachowi (Van der Hoeven et al. 1982, Van der Kerkhoff \& Van der Gaag 1985), the 
polychaetes Neanthes arenaceodentata (Pesch et al. 1981) and Platynereis dumerilii (Jha et al. 1996), and the mussels Mytilus edulis (Dixon \& Clarke 1982, Harrison \& Jones 1982) and $M$. galloprovincialis (Brunetti et al. 1986) were used as model systems to apply this feasible cytogenetic test for determining chemically induced genetic damage.

Many of the undertaken studies of SCE in marine organisms used early life-history stages (Pesch et al. 1981, Harrison \& Jones 1982, Brunetti et al. 1986, Dixon \& Prosser 1986, Jones \& Harrison 1987, Jha et al. 1996) because such material presents the advantage of a high yield of dividing cells with a short cell cycle. On the other hand, the small size of developing eggs and larvae and their potential mobility pose serious practical constraints on their usefulness in field monitoring (Dixon \& Clarke 1982).

As pointed out by Dixon \& Clarke (1982) and Harrison \& Jones (1982), the ubiquity of mussels, their capacity for bioconcentration and their sedentary adult life make them an excellent choice for SCE studies monitoring genetic pollutants in estuarine and marine environments. In this paper, we present results of a series of mussel SCE assays that indicate factors other than BrdU concentration have a large influence on the baseline SCE frequency.

\section{MATERIAL AND METHODS}

Test animals. The assays were carried out with the mussel species Mytilus galloprovincialis Lmk. $(2 \mathrm{n}=28$ chromosomes). Mussels ( 1 to $2 \mathrm{~cm}$ shell length) were collected from an intertidal population at Balcobo (Galicia, NW Spain). They were maintained for $12 \mathrm{~d}$ in the laboratory in $5 \mathrm{l}$ tanks of aerated, filtered sea water at $20 \pm 1^{\circ} \mathrm{C}$, and they were fed on a suspension of mixed algal cells (Tetraselmis suecica, Isochrysis galbana, and Phaeodactilum tricornutum) before any treatment was started. In addition, mussels sized 1 to $2 \mathrm{~cm}$ were collected monthly in 1993 at Balcobo and from another intertidal population at Mera (Galicia, NW Spain) and maintained in sea water obtained from the same places where mussels were taken.

BrdU incorporation. Two experimental protocols were used to investigate the effect of different BrdU treatments on SCE frequency in mussel gill cells. The first was the most common method for the investigation of SCEs, a continuous treatment with BrdU in sea water to allow gill cell DNA to replicate twice. In the second protocol, cells were labelled with BrdU only for the first round of replication; this was followed by a second cell cycle without BrdU.

The effect of $4 \mathrm{BrdU}$ concentrations was analyzed in dose response experiments. Four groups, each com- prising 15 mussels with similar size distributions, were housed in tanks containing $0.75 \mathrm{l}$ of, respectively, 4,10 , 20 and $40 \mu \mathrm{g} \mathrm{ml}^{-1}$ BrdU in sea water for $60 \mathrm{~h}(60 \mathrm{~h}$ treatments). Four more groups of 15 mussels were first treated with BrdU $\left(4,10,20\right.$ and $\left.40 \mu \mathrm{g} \mathrm{ml}^{-1}\right)$ for $24 \mathrm{~h}$ and, after that, maintained for $36 \mathrm{~h}$ in clean sea water $(24+36$ h treatments)

To investigate the effect of the duration of the BrdU treatment on SCE frequency in mussel gill cells we again used the 2 experimental protocols already described. Five groups of 15 mussels were housed in tanks containing $0.75 \mathrm{l}$ of $4 \mu \mathrm{g} \mathrm{m} \mathrm{m}^{-1} \mathrm{BrdU}$ in sea water for $48,60,72,84$ and $96 \mathrm{~h}(48,60,72,84$ and $96 \mathrm{~h}$ treatments). Five more groups of 15 mussels from Balcobo were first treated with BrdU for 12, 12, 24, 24 and $36 \mathrm{~h}$ and, after that, maintained for $36,48,24,36$ and $24 \mathrm{~h}$, respectively, in clean sea water $(12+36,12+48,24+24$, $24+36$, and $36+24 \mathrm{~h}$ treatments). Because of the asynchrony in the gill cell population division, all the time exposures yielded enough complete sister chromatid differentiated (SCD) metaphases for analysis of SCE (Martínez-Expósito et al. 1994).

To detect possible variations in SCE frequencies throughout the year in natural populations, mussels were collected monthly (January to December 1993) at Balcobo and also from another intertidal population at Mera. The laboratory conditions were maintained as already described, except that unfiltered sea water from the collection localities was used. Every month, 15 mussels from each locality were treated for $60 \mathrm{~h}$ with $4 \mu \mathrm{g} \mathrm{ml}^{-1}$ BrdU.

In all experiments the water containing BrdU was changed every $12 \mathrm{~h}$. At $10 \mathrm{~h}$ before the end of each experiment, colchicine $(0.005 \%)$ was added.

Differential staining procedure. Following the colchicine treatment, the mussels were briefly rinsed and the gills were excised, immersed in diluted sea water for $1 \mathrm{~h}$ and fixed in Carnoy's fixative for $1 \mathrm{~h}$. Chromosome spreads were obtained by dissociating gill tissue in $45 \%$ acetic acid and pipetting suspension drops onto slides heated to $43^{\circ} \mathrm{C}$. The slides were air-dried and aged for at least $24 \mathrm{~h}$ before differential staining.

A modification of the FPG method (Perry \& Wolff 1974) was used for the differential staining of the chromosomes (Martínez-Expósito et al. 1994). In brief, slides aged 1 to $7 \mathrm{~d}$ were stained with $0.4 \mu \mathrm{m} \mathrm{m}^{-1}$ Hoechst 33258 (Sigma) in $0.5 \times \mathrm{SSC}$ (sodium chloride/sodium citrate buffer) for $15 \mathrm{~min}$, rinsed in $0.5 \times \mathrm{SSC}$ and mounted in the same solution before being exposed to a $15 \mathrm{~W}$ blacklight (Sylvania) for $15 \mathrm{~min}$. After removal of the coverslips, slides were immersed in $0.5 \times \mathrm{SSC}$ at $60^{\circ} \mathrm{C}$ for $15 \mathrm{~min}$, rinsed in distilled water and stained in 10\% Giemsa (Carlo Erba) in phosphate buffer, $\mathrm{pH} 6.88$, for $30 \mathrm{~min}$.

Scoring procedure. SCE frequencies were scored only in well-spread metaphases containing 28 chromo- 


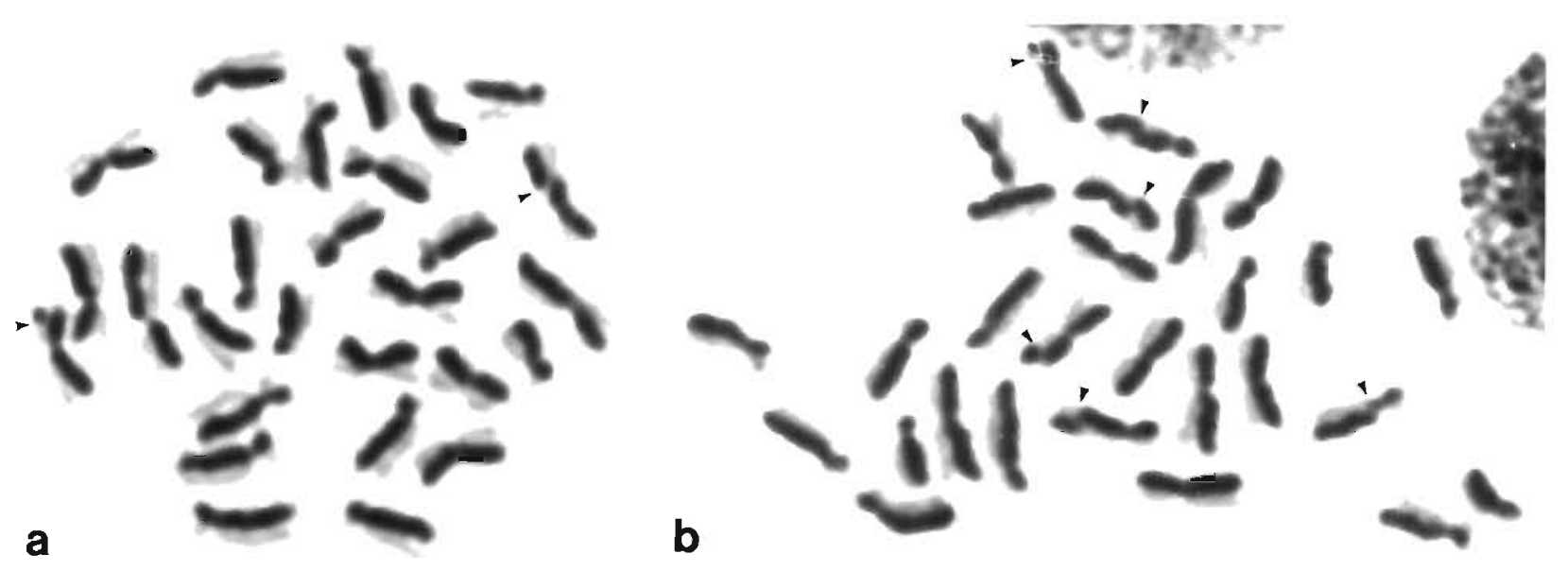

Fig. 1. Mytilus galloprovincialis. Mitotic metaphase chromosomes from mussel gill cells showing sister chromatid differentiation and different number of SCE (arrowheads) after (a) $24+36 \mathrm{~h}$ and (b) $84 \mathrm{~h}$ BrdU treatments

somes. For the $24+36,36+24,60,72,84$ and $96 \mathrm{~h}$ BrdU treatments, SCE counts were made in 50 metaphases in each one of the 90 mussels (15 per treatment). Because of the relatively low yield of complete SCD metaphases, only 20 metaphases per mussel were analysed in the $12+36,12+48,24+24$ and 48 h exposure treatments. For the dose response and the year-long experiments, 20 metaphases per mussel were also studied. Slides were scored blind and SCE counts were made directly from the slides under a Nikon Optiphot microscope with a $100 \times$ plan apochromatic oil-immersion objective, using a green filter to enhance contrast.

Data analysis. The method of analysis involved a variance stabilizing transformation of the SCE data, where each individual count was replaced by $\ln (1+\mathrm{SCE})$, followed by 2 -way or 1 -way ANOVA or Student's t-test (Sokal \& Rohlf 1981). Statistical calculations were carried out with the SPSS/PC package.

\section{RESULTS}

As SCE counts are limited to complete metaphases without overlapping chromosomes, it is important to maximise the number of well-spread metaphase cells. Good chromosome morphology is also critical. Our experimental conditions provided an adequate number of SCD metaphases ( 7.5 to $10 \%$ ) after $24+36$, $36+24,60,72,84$, and $96 \mathrm{~h}$ BrdU exposures, thus, 50 fully SCD complete metaphases with non-overlapping chromosomes could be analysed for every mussel. For the $12+36,12+48,24+24$ and 48 h BrdU exposures, the yields of this kind of metaphase were lower ( 1.5 to $2.3 \%$ ) and, consequently, 20 metaphases per mussel were analysed. SCD metaphases with different numbers of SCE are shown in Fig. 1.

\section{Dose-response experiments}

The results presented in Fig. 2 show that BrdU induced a linear SCE dose-response over the range of concentrations tested after both $24+36$ and 60 h treatments. ANOVA of transformed data in Fig. 2 (Table 1) shows significant effects due to both BrdU concentration and incorporation protocol, but no interaction between them was detected. Taking these results into account, 1-factor ANOVA was used to further analyse the effect of BrdU dose in the SCE frequencies obtained after the $24+36$ and $60 \mathrm{~h}$ BrdU treatments. A significant dose-dependent increase in the baseline level of SCE was detected for the 2 BrdU incorporation protocols performed. In both cases, no significant differences in SCE frequencies were detected for treatments between 4 and $10 \mu \mathrm{g} \mathrm{m}^{-1} \mathrm{BrdU}, 20 \mu \mathrm{g} \mathrm{ml}^{-1} \mathrm{BrdU}$ being the lowest dose of BrdU to induce a significant response in mean SCE frequency.

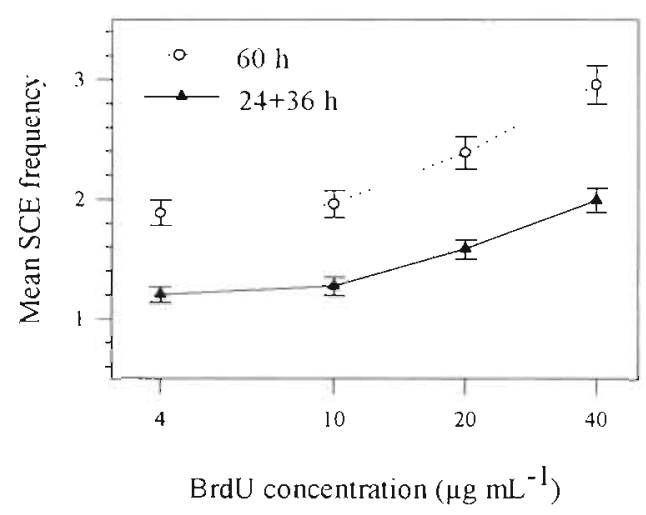

Fig. 2. Mytilus galloprovincialis. Mean SCE frequencies in mussels exposed to 4 different BrdU concentrations for $24+36$ and $60 \mathrm{~h}$ (see text) 
Table 1. ANOVA of the effect of the exposure and concentration of BrdU on SCE frequency. ' $p<0.001$

\begin{tabular}{|lrrrr|}
\hline Source of variation & SS & df & MS & \multicolumn{1}{c|}{$F$} \\
\cline { 1 - 4 } BrdU exposure & 44.99 & 1 & 44.99 & $1708.10 \cdots$ \\
BrdU concentration & 40.97 & 3 & 13.66 & $35.52 \cdots$ \\
Interaction & 0.08 & 3 & 0.03 & $0.07 \cdots$ \\
Within BrdU conc. by & & & & \\
exposure & 43.07 & 112 & 0.38 & \\
Within mussels & 356.77 & 2280 & 0.16 & \\
Total & 485.88 & 2399 & & \\
\hline
\end{tabular}

In addition, Fig. 2 shows that at a fixed concentration of BrdU differences due to the BrdU incorporation protocol are also noticeable. Student's $t$-test applied to the transformed data obtained for each BrdU dose demonstrated that the SCE frequencies obtained after $60 \mathrm{~h}$ treatments ( 2 consecutive cycles of BrdU incorporation) are always significantly higher than those obtained after $24+36 \mathrm{~h}$ treatments (only a first replication round incorporating BrdU).

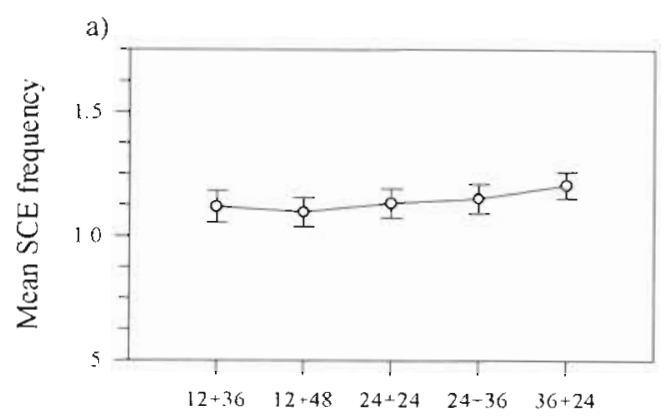

b)

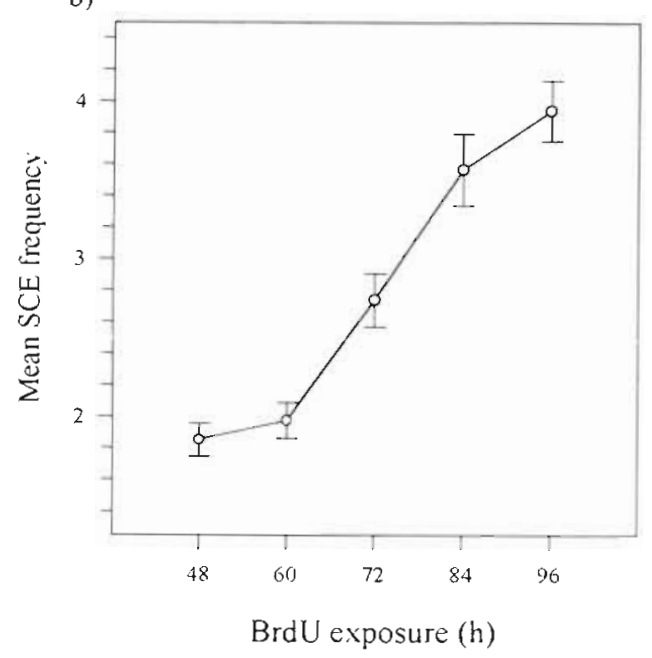

Fig. 3. Mytilus galloprovincialis. Effect of the length of the BrdU treatment on SCE frequencies in mussels: (a) first replication round of BrdU treatment followed by a second round without $\mathrm{BrdU}$; (b) 2 consecutive replication rounds of BrdU treatment
The results also demonstrate a remarkable interindividual variability in the response of the mussels to equal BrdU dose and exposure conditions. Significant differences in SCE frequencies among mussels were found after every $60 \mathrm{~h}$ treatment $(4,10,20$ and $40 \mu \mathrm{g}$ $\mathrm{ml}^{-1}$ ) and after all but one of the $24+36 \mathrm{~h}$ treatments $\left(10,20\right.$ and $\left.40 \mu \mathrm{g} \mathrm{ml}^{-1}\right)$. No significant differences were found among mussels treated with $4 \mu \mathrm{g} \mathrm{m}^{-1} \mathrm{BrdU}$ for $24+36 \mathrm{~h}$. At the same time, a high degree of intraindividual variability was also noted in the SCE counts of cells from each mussel.

Taking into account the previous results, a BrdU concentration of $4 \mu \mathrm{g} \mathrm{ml}^{-1}$ was selected for all subsequent studies. This concentration provided good SCD, good mitotic index and a low baseline SCE frequency.

\section{Incorporation time experiments}

BrdU incorporation for a first round of replication

The mean values of SCE per metaphase for the 5 BrdU treatments analysed $(12+36,12+48,24+24$, $24+36$ and $36+24 \mathrm{~h}$ ) are shown in Fig. 3a. ANOVA of these data did not show significant differences in SCE frequencies among treatments, or among mussels within treatments for $12+36,12+48$ and $24+24$ h treatments. In contrast, significant differences among mussels within treatments were detected after $24+36$ and $36+24$ h exposures

\section{BrdU incorporation for 2 consecutive rounds of replication}

Fig. 3b shows that, for mussels, the length of the continuous BrdU treatment is an important factor in determining the yields of SCE frequencies. One-factor ANOVA of data in Fig. $3 \mathrm{~b}$ shows significant differences due to the length of the BrdU exposure, but there were no significant differences in the frequencies of SCE after the 48 and $60 \mathrm{~h}$ BrdU treatments. Significant differences in SCE frequencies among mussels were detected after the 60, 72, 84 and $96 \mathrm{~h}$ BrdU treatments but not after the $48 \mathrm{~h}$ exposure.

\section{Monthly analysis of SCE frequencies}

Fig. 4 shows monthly mean values of SCE per cell in 2 natural populations throughout 1993 after $60 \mathrm{~h} \mathrm{BrdU}$ exposure. A remarkable degree of variation is clearly seen both between sites and among months. Mussels from Balcobo showed a maximum SCE frequency in June $\left(2.85 \pm 0.30 \mathrm{SCE}\right.$ cell $\left.{ }^{-1}\right)$ and minima both in Janu- 


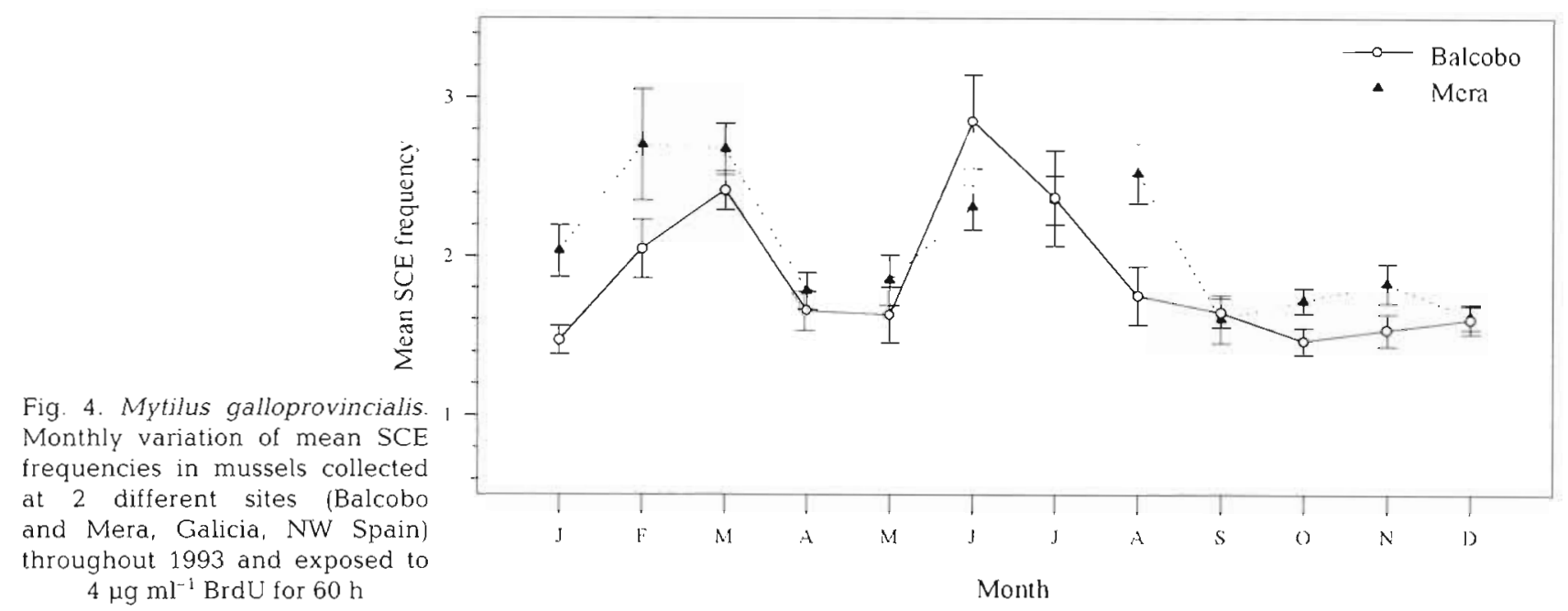

Table 2. ANOVA of the effect of collection site and month on SCE frequency. " $p<0.05$

\begin{tabular}{|lrrrr|}
\hline Source of variation & \multicolumn{1}{c}{ SS } & df & MS & $F$ \\
\hline Site & 10.94 & 1 & 10.94 & $5.60^{\circ}$ \\
Month & 88.66 & 11 & 8.06 & $4.13^{\circ}$ \\
Interaction & 21.49 & 11 & 1.95 & $2.81^{\circ}$ \\
Within site by month & 233.35 & 336 & 0.69 & \\
Within mussels & 1698.52 & 6840 & 0.25 & \\
Total & 2049.96 & 7199 & & \\
\hline
\end{tabular}

ary $\left(1.47 \pm 0.09 \mathrm{SCE}\right.$ cell $\left.{ }^{-1}\right)$ and October $(1.47 \pm 0.08$ $\mathrm{SCE}$ cell $\left.{ }^{-1}\right)$. Data from Mera show a maximum in February $\left(2.70 \pm 0.35 \mathrm{SCE}\right.$ cell $\left.{ }^{-1}\right)$ and a minimum in September $\left(1.61 \pm 0.15 \mathrm{SCE}\right.$ cell $\left.^{-1}\right)$. Statistical analysis of the transformed data in Fig. 4 (Table 2) shows significant differences in SCE frequencies among months and between collection sites. A significant interaction between months and collection sites was also detected. Again, significant differences among mussels were detected for some months for both the Balcobo (February to August, December) and Mera (January, February, May to September) populations.

\section{DISCUSSION}

Because different tissues proliferate at different rates, one must have sufficient knowledge concerning the rate of cell division for a specific tissue before performing SCE assays. In a previous work (MartínezExpósito et al. 1994), we experimentally established that 24 to $30 \mathrm{~h}$ is the length of the cell cycle in gill cells of Mytilus galloprovincialis, and that a $48 \mathrm{~h} \mathrm{BrdU}$ exposure is long enough for some cells $(2.34 \%)$ to show full
SCD. In these SCD metaphases each chromosome presents a bifilarly substituted chromatid showing pale Giemsa staining and an unifilarly substituted one that is stained darker. In the same work, we also demonstrated that the asynchronous proliferation of mussel gill cells permits SCD metaphases to be obtained using longer BrdU treatments (60 to $96 \mathrm{~h}$ ). On the other hand, the knowing the cell cycle length permits full SCD metaphases to be obtained using a different experimental approach. One replication round in the presence of BrdU, followed by a second replication round in its absence results in chromosomes presenting one sister chromatid unsubstituted (dark) and the other unifilarly substituted (pale). The use of this incorporation protocol allowed us to obtain SCD metaphases after 12 to $36 \mathrm{~h}$ BrdU exposures.

One of the toughest dilemmas facing biologists is estimating the actual incidence of SCE occurring in nature because the chemicals used for detection are known inducers of SCE. In aquatic species, SCE has been studied with the intention of developing assays to monitor the aquatic environment for mutagens. Several investigators have calculated BrdU-dependent dose response curves in order to determine baseline levels of SCE in some test systems (Kligerman \& Bloom 1976, Harrison \& Jones 1982, Dixon \& Prosser 1986). In the study of mussels, most previous SCE studies have focused upon early developmental stages to ensure an adequate number of dividing cells for analysis. In those works, dose responses to BrdU were analysed. Mytilus edulis $12 \mathrm{~h}$ old larvae exposed to $10^{-5}$ to $10^{-4} \mathrm{M} \mathrm{BrdU}$ for $12 \mathrm{~h}$ exhibited a linear SCE dose response (Harrison \& Jones 1982). Significant increases in SCE frequency due to the BrdU concentration were also demonstrated by Dixon \& Prosser (1986) using a similar experimental protocol. Higher BrdU concentrations $\left(10^{-3}\right.$ and $\left.2 \times 10^{-3} \mathrm{M}\right)$ were used by Brunetti et al. (1986) 
for SCE analyses in developing eggs of $M$. galloprovincialis, but the differences in the SCE frequencies obtained were not significant. To our knowledge, only Dixon \& Clarke (1982) and Dixon et al. (1985) have analysed SCE in adults of a species of mussel. They exposed adult $M$. edulis to $5 \times 10^{-5} \mathrm{M}$ BrdU for 96 and $120 \mathrm{~h}$, respectively, to obtain a significant proportion of gill cells with SCD

Our results are in accordance with those in the literature in the sense that SCE frequency varies in a dosedependent manner both after $24+36$ and $60 \mathrm{~h}$ BrdU treatments (Fig. 2, Table 1). At the same time, BrdU concentrations of 4 and $10 \mu \mathrm{g} \mathrm{ml}^{-1}$ (equivalent to $1.3 \times$ $10^{-5}$ and $3.25 \times 10^{-5} \mathrm{M}$ BrdU respectively) did not induce significant differences in SCE frequencies in mussel gill cells. These BrdU doses are similar to those employed in previous studies using adult $\left(5 \times 10^{-5} \mathrm{M}\right.$ BrdU; Dixon \& Clarke 1982, Dixon et al. 1985) and larval $\left(10^{-5}\right.$ to $10^{-4} \mathrm{M}$ BrdU; Harrison \& Jones 1982 , Dixon \& Prosser 1986, Jones \& Harrison 1987) Mytilus edulis but lower than those used in developing eggs of $M$. galloprovincialis $\left(10^{-3}\right.$ and $2 \times 10^{-3} \mathrm{M} \mathrm{BrdU}$; Brunetti et al. 1986). In addition, Fig. 2 shows that at a fixed concentration of BrdU significantly higher SCE frequencies were found when the exposure protocol allowed BrdU incorporation for 2 consecutive replication rounds. This is also in accordance with previous data coming from other material (Natarajan et al. 1981, Cortés \& Andersson 1987), and the increase in SCE frequency was interpreted as a result of the replication (incorporating BrdU) on a BrdU-containing template during the second round of synthesis.

In aquatic organisms, the possible influence of the length of the BrdU treatment on SCE frequency has not been studied. Moreover, an examination of the treatments used in vivo for differential chromatid staining reveals extreme variation, even for the same species (Kligerman 1979, Alink et al. 1980, Dixon \& Clarke 1982, Van der Hoeven et al. 1982, Dixon et al. 1985, Van der Kerkhoff \& Van der Gaag 1985). The 2 experimental approaches used in this work in order to examine the influence of the duration of the BrdU exposure on SCE frequency gave different results. Treatments performed in order to obtain metaphase cells that incorporate BrdU only for a first round of replication (Fig. 3a) did not show significant differences in SCE frequencies. On the contrary, we found a length-dependent increase in the frequency of SCE when BrdU incorporation took place for 2 consecutive rounds of replication (Fig. 3b). No differences were found between 48 and $60 \mathrm{~h}$ treatments. Because the BrdU incorporation method used involves the renewing of the BrdU solution every $12 \mathrm{~h}$, at least part of the increase in the SCE frequency could be attributed to the effect of a higher amount of BrdU available to the mussel gill cells. This explanation could not be applied to the first cycle incorporation approach even though the total amount of BrdU available is 3 times higher for the $36+24 \mathrm{~h}$ exposure than for those of $12+36$ and $12+48 \mathrm{~h}$. At the same time, mean SCE frequency obtained for Mytilus galloprovincialis after the $96 \mathrm{~h}$ treatment $\left(3.94 \pm 0.19 \mathrm{SCE}\right.$ cell $\left.{ }^{-1}\right)$ is roughly similar to that reported by Dixon \& Prosser (1986) in $M$. edulis after a continuous $96 \mathrm{~h} \mathrm{BrdU}$ treatment (4.1 SCE cell ${ }^{-1}$ ), in spite of the differences affecting the concentration and renewal of the BrdU solution and the species of Mytilus employed.

On the other hand, SCE frequencies detected monthly in mussels collected at 2 different sites throughout 1993 show a quite high degree of variation both within and between populations. Results did not show any clear pattern of seasonal variability that could be related to the water temperature as was the case for another genotoxicity assay, the micronucleous test, in Mytilus galloprovincialis coming from 2 Mediterranean areas (Migliore et al. 1989, Brunetti et al. 1992). Although differences due to the water temperature could be masked by the maintenance of the mussels in the laboratory for $12 \mathrm{~d}$ at $20^{\circ} \mathrm{C}$, this is probably not the case. The 2 collection sites showed similar water temperatures, from a minimum of 12 to $13^{\circ} \mathrm{C}$ in full winter to a maximum of 18 to $19^{\circ} \mathrm{C}$ in full summer, but differences in SCE frequencies were found in mussel collected in months in which the temperature of the water was almost the same. These results seem to indicate that other factors have a larger influence on baseline SCE levels in juvenile $M$. galloprovincialis.

The SCE frequencies obtained in this work also demonstrate a remarkable variability among individuals exposed to the same BrdU concentration for the same length of time, some individuals presenting 2 to 2.5 times more SCE than others. For example, in a total of 26 groups of 15 mussels exposed to $4 \mu \mathrm{g} \mathrm{ml}^{-1} \mathrm{BrdU}$ for $60 \mathrm{~h}$, significant differences among mussels were found in 17 groups and no significant differences were found for the other 9 . These results are somewhat in accordance with the high variability in the frequency of SCE found by Jones \& Harrison (1987) among groups of Mytilus edulis larvae with different parents. Although the variations found in juvenile $M$. galloprovincialis were rather lower than those in $M$. edulis Iarvae, the results obtained in this work reinforce the fact that factors affecting baseline SCE frequency in mussels have to be studied before using this assay as a routine test to monitor marine contamination.

It should be also noted that the average SCE frequencies per cell obtained after 4 and $10 \mathrm{\mu g} \mathrm{ml}^{-1} \mathrm{BrdU}$ exposures for $60 \mathrm{~h}$ in adult mussel are roughly similar to some previously published results. In contrast, mean SCE frequencies for the $24+36 \mathrm{~h}$ experiments are 
lower than most of those reported for other aquatic organisms and for developing eggs of $M$. galloprovincialis (Brunetti et al. 1986), and only some of the studies using $M$. edulis larvae (Harrison \& Jones 1982, Dixon \& Prosser 1986) showed similar values.

Because SCE frequencies in juvenile mussels increase with longer BrdU treatments, caution has to be taken in extending the BrdU exposure time in order to obtain higher yields of SCD metaphases. A continuous BrdU incorporation time of $60 \mathrm{~h}$ or incorporation of BrdU for the first replication round followed by a second cell cycle without BrdU $(24+36 \mathrm{~h})$ would seem to be most appropriate for the SCE tests carried out in gill cells of Mytilus galloprovincialis. While, as pointed out by Dixon \& Clarke (1982), SCE analysis remains a valuable tool for investigating the susceptibility of marine organisms to genetic damage by specific or mixed environmental contaminants, the temporal and spatial variation in SCE frequencies obtained in this work poses new difficulties to be overcome before the SCE method can be translated directly to the field.

Acknowledgements. We thank Ms A. Naya-Costa for her technical assistance and Dr Rolán-Álvarez for his comments on statistical analysis. We also thank the members of Área de Microbioloxía, Universidade da Coruna, for kindly supplying cultured algae. This work was supported in part by Direccion General de Ciencia y Tecnología (Spain).

\section{LITERATURE CITED}

Alink GM, Frederix-Wolters EM, Van der Gaag MA, Van de Kerkhoff JFJ, Poels CLM (1980) Induction of sister chromatid exchanges in fish exposed to Rhine water. Mutat Res 78:369-374

Brunetti R, Gabriele M, Valerio P, Fumagalli O (1992) The micronucleus test: temporal pattern of base-line frequency in Mytilus galloprovincialls. Mar Ecol Prog Ser 83:75-78

Brunetti R, Gola I. Majone F (1986) Sister-chromatid exchange in developing eggs of Mytilus galloprovincialis Lmk. (Bivalvia). Mutat Res 174:207-211

Cortés F, Andersson HC (1987) Analysis of SCEs in Vicia faba chromosomes by a simple fluorescent plus Giemsa technique. Hereditas 107:7-13

Dixon DR, Clarke KR (1982) Sister chromatid exchange: a sensitive method for detecting damage caused by exposure to environmental mutagens in the chromosomes of adult Mytilus edulis. Mar Biol Lett 3:163-172

Dixon DR, Jones IM, Harrison FL (1985) Cytogenetic evi-

This article was submitted to the editor dence of inducible processes linked with metabolism of a xenobiotic chemical in adult and larval Mytilus edulis. Sci Total Environ 46:1-8

Dixon DR, Prosser H (1986) An investigation of the genotoxic effects of an organotin antifouling compound (bis(tributyltinjoxide) on the chromosomes of the edible mussel, Mytilus edulis. Aquat Toxicol 8:185-195

Harrison FL, Jones IM (1982) An in vivo sister-chromatid exchange assay in the larvae of the mussel Mytilus edulls: response to 3 mutagens. Mutat Res 105:235-242

Jha AN, Hutchinson TH, Mackay JM, Elliott BM, Dixon DR (1996) Development of an in vivo genotoxicity assay using the marine worm Platynereis dumerelii (Polychaeta: Nereidae). Mutat Res 359:141-150

Jones IM, Harrison FL (1987) Variability in the frequency of sister-chromatid exchange in larvae of Mytilus edulis: implications for field monitoring. J Exp Mar Biol Ecol 113: $283-288$

Kligerman AD (1979) Induction of sister chromatid exchanges in the central mudminnows following in vivo exposure to mutagenic agents. Mutat Res 64:205-217

Kligerman AD, Bloom SE (1976) Sister chromatid exchanges in adult mudminnows (Umbra limi) after in vivo exposure to 5-bromodeoxyuridine. Chromosoma (Berl) 56:101-109

Martínez-Expósito MJ, Pasantes JJ, Méndez J (1994) Proliferation kinetics of mussel (Mytilus galloprovincialis) gill cells. Mar Biol 120:41-45

Migliore L., Di Marino F, Scarpato R, Barale R, CognettiAlfinito $G$ (1989) Detection of mutagenuc/carcinogenic compounds in the marine environment. In: Grandjean E (ed) Carcinogenic, mutagenic, and teratogenic marine pollutants: impact on human health and the environment. Advances in applied biotechnology series, Vol 5. Portfolio Publ Co, The Woodlands, TX, p 111-120

Natarajan AT, Csukás l, Van Zeeland AA (1981) Contribution of incorporated 5-bromodeoxyuridine in DNA to the frequencies of sister-chromatid exchanges induced by inhibitors of poly-(ADP-ribose)-polymerase. Mutat Res 84: $125-132$

Perry P, Wolff S (1974) New Giemsa method for the differential staining of sister chromatids. Nature 251:156-158

Pesch GG, Pesch CE, Malcolm AR (1981) Neanthes arenaceodentata, a cytogenetic model for marine genetic toxicology. Aquat Toxicol 1:301-311

Schneider EL, Tice RR, Kram D (1978) Bromodeoxyuridine differential chromatid staining technique: a new approach to examining sister chromatid exchange and cell replication kinetics. Methods Cell Biol 20:379-409

Sokal RR, Rohlf FJ (1981) Biometry. Freeman, San Francisco

Van der Hoeven JCM, Bruggeman IM, Alink GM, Koeman JH (1982) The killifish Nothobranchius rachowi, a new animal in genetic toxicology. Mutat Res 97:35-42

Van de Kerkhoff JFJ, Van der Gaag MA. (1985) Some factors affecting optimal differential staining of sister chromatids in vivo in the fish Nothobranchius rachowi. Mutat Res 143: $39-43$

Manuscript first received: July 1, 1996

Revised version accepted: September 17, 1996 